\title{
A Teoria das Representações Sociais nos estudos sobre formação de professores na Educação Física: mapeando a produção do conhecimento nos periódicos brasileiros
}

\section{RESUMO}

O objetivo do manuscrito é contribuir para as discussões acerca da formação de professores de educação física do ponto de vista da Teoria das Representações Sociais, identificando como a teoria vem sendo disseminada nas principais produções periódicas da área. Para tal, apresenta um levantamento com base nos principais periódicos da área de Educação Física/ Ciências do Esporte. Os resultados desvelam que foram publicados 12 estudos entre 2002 e 2020, tendo sido observado que as produções sobre representações sociais da formação de professores na educação física têm se apropriado de diferentes referenciais, abordagens e métodos que compõem o arcabouço teórico do paradigma das representações sociais. O manuscrito sugere que a Teoria das Representações Sociais está disseminada nas produções periódicas da área.

PALAVRAS-CHAVE: Representação social;

Formação docente; Produção científica
Felipe da Silva Triani

Mestre em Humanidades, Culturas e Artes -

UNIGRANRIO

Universidade Estácio de Sá,

Rio de Janeiro, Brasil

felipetriani@gmail.com

(ㄴ) https://orcid.org/0000-0001-6470-8823 
The Theory of Social Representations in studies on the training of Physical Education teachers: mapping the production of knowledge in Brazilian journals

\begin{abstract}
The objective of the manuscript is to contribute to the discussions about the training of physical education teachers from the point of view of the Theory of Social Representations, identifying how the theory has been disseminated in the main periodic productions in the area. To this end, it presents a survey based on the main journals in the area of Physical Education / Sport Sciences. The results reveal that 12 studies were published between 2002 and 2020, and it was observed that the productions on social representations of teacher education in physical education have appropriated different references, approaches and methods that make up the theoretical framework of the social representations paradigm. The manuscript suggests that the Theory of Social Representations is widespread in periodic productions in the area.
\end{abstract}

KEYWORDS: Social representation; Teacher training; Scientific production

La teoría de las representaciones sociales en los estudios sobre formación docente en educación física: mapeo de la producción de conocimiento en revistas brasileñas

\title{
RESUMEN
}

El objetivo del manuscrito es contribuir a las discusiones sobre la formación de profesores de educación física desde el punto de vista de la Teoría de las Representaciones Sociales, identificando cómo se ha difundido la teoría en las principales producciones periódicas en el área. Con este fin, presenta una encuesta basada en las principales revistas en el área de Educación Física / Ciencias del Deporte. Los resultados revelan que se publicaron 12 estudios entre 2002 y 2020, y se observó que las producciones sobre representaciones sociales de la formación docente en educación física se han apropiado de diferentes referencias, enfoques y métodos que conforman el marco teórico del paradigma de las representaciones sociales. El manuscrito sugiere que la Teoría de las representaciones sociales está muy extendida en producciones periódicas en el área.

PALABRAS-CLAVE: Representación social; Formación del profesorado; Producción científica 


\section{INTRODUÇÃO}

A Teoria das Representações Sociais, proposta por Serge Moscovici em La Psychanalyse, sonimageetsonpublic, na Europa, em 1961, tem servido enquanto referencial teórico e metodológico para o campo acadêmico/científico da Educação Física/Ciências do Esporte. Dentre as possíveis contribuições da teoria para a área, destacam-se suas possibilidades de estudos do/com/no cotidiano no campo de intervenção pedagógica e científica da educação física (TRIANI; NOVIKOFF, 2020).

A partir de uma crítica à sociologia e psicologia da época, Moscovici (2012) propõe um campo denominado de Psicologia Social, o qual, a partir da Teoria das Representações Sociais teria as representações sociais como objeto de estudo. Nesse cenário, foi Jodelet (2001, p. 22) quem propôs o conceito mais popular presente no âmago dos estudos em representações sociais, sendo assim, trata-se de "uma forma de conhecimento, socialmente elaborada e partilhada, com um objetivo prático, e que contribui para a construção de uma realidade comum a um conjunto social". Logo, para Moscovici (2009), as representações sociais são uma "teoria do senso comum", pois busca trazer para a discussão científica os conhecimentos do senso comum compartilhados por indivíduos e grupos sociais, os quais exercem influência sobre suas práticas e comportamentos da vida cotidiana.

Historicamente, de acordo com Sá e Arruda (2000), os conhecimentos relativos à Teoria das Representações Sociais chegam ao Brasil por duas vias: a primeira faz referência aos brasileiros que participaram de cursos ministrados por Serge Moscovici e Denise Jodelet na Escola de Altos Estudos em Ciências Sociais, em Paris, nos anos 70; já a segunda corresponde à visita de Jodelet ao Brasil em 1982. Além disso, os autores destacam que durante a década de 90, por meio de conferências, jornadas e encontros acadêmico/científicos, a teoria foi amplamente difundida no Brasil, com ênfase no Rio de Janeiro, chegando a ser considerada como um "modismo". Adicionalmente, Sousa et al (2018) inferem que a apropriação da teoria pelo campo da Educação Física segue o mesmo movimento, ou seja, concentra-se no Rio de Janeiro.

De acordo com Alves-Mazzotti (2008), as investigações sobre a formação de professores do ponto de vista da Teoria das Representações Sociais assume relevância na medida em que permite orientar políticas direcionadas à formação inicial e continuada do professor. Contudo, ao revisitar a literatura concernente à temática, foram encontrados dois estudos de revisão (SOUSA et al., 2018; TRIANI; NOVIKOFF, 2020). O primeiro, embora tenha abordado a Teoria das Representações Sociais no campo da Educação Física, não foi direcionado à formação de professores; já o segundo, embora tenha tematizado a teoria, a formação de professores e a educação física, ateve-se às 
produções relativas às dissertações e teses. Diante desses entendimentos, percebe-se a necessidade de uma revisão que investigue a apropriação da referida teoria pela Educação Física. Logo, o objetivo do manuscrito é contribuir para as discussões acerca da formação de professores de educação física do ponto de vista da Teoria das Representações Sociais, identificando como a teoria vem sendo disseminada nas principais produções periódicas da área.

\section{METODOLOGIA}

O estudo em tela pode ser denominado de estado do conhecimento, pois aborda somente um setor das publicações sobre o objeto (ROMANOWSKI; ENS, 2006). De acordo com Triani e Novikoff (2020), o estado do conhecimento pode ser compreendido como uma investigação quantitativa e qualitativa, sendo quantitativa em razão do levantamento numérico das produções. E, qualitativo enquanto discussão temática a partir da trajetória e distribuição da produção científica sobre um determinado objeto, estabelecendo relações contextuais com um conjunto de outras variáveis como, por exemplo, referencial teórico, metodologia utilizada, técnica de coleta de dados e etc.

Nesta perspectiva, o estado do conhecimento foi adotado no presente texto para identificar a situação atual em que a produção científica em periódicos da educação física brasileira se encontra acerca das pesquisas produzidas sobre formação de professores que adotaram a Teoria das Representações Sociais como referencial teórico e metodológico no seu desenvolvimento. Desse modo, entende-se aqui como produção científica em periódicos da educação física brasileira os trabalhos publicados nas 12 principais revistas científicas do campo da educação física listadas por Lazzarotti Filho (2018), são elas: Revista Brasileira de Ciências do Esporte (RBCE); Revista Brasileira de Educação Física e Esporte (RBEFE); Revista Brasileira de Ciência e Movimento; Motrivivência; Revista da Educação Física (REF-UEM); Movimento; Motriz; Revista Brasileira de Atividade Física e Saúde; Pensar a Prática; Licere; Conexões: Educação, Esporte e Lazer; Revista de Cineantropometria e Movimento Humano.

Para a composição do estudo, não se realizou um recorte temporal, pois todos os artigos publicados nos periódicos selecionados com a temática em questão foram considerados. A busca pelos artigos sobre representações sociais, formação de professores e educação física foi realizada, de forma independente, durante todo o primeiro semestre do ano de 2020. No instrumento de busca na página virtual de cada revista foram inseridos os descritores "Representações sociais" e “representação social”, a fim de se refinar a pesquisa. 
A seleção dos artigos foi feita com base no título, nas palavras-chave, nos resumos e, em última análise, na leitura dos textos na íntegra. Adicionalmente, os textos que utilizaram as expressões "representação social" e "representações sociais" sem vinculado com a Teoria das Representações Sociais não foram selecionados. Essa estratégia permitiu encontrar 50 manuscritos, sendo 4 na RBCE, 8 na RBEFE, 11 na Motrivivência, 2 na REF-UEM, 5 na Motriz, 8 na Movimento, 9 na Pensar a Prática e 3 na Conexões. Nenhuma produção relativa à temática foi encontrada nos periódicos: Revista Brasileira de Ciência e Movimento; Licere; Revista Brasileira de Atividade Física e Saúde; e Revista Brasileira de Cineantropometria e Movimento Humano.

Os 50 artigos identificados foram submetidos à leitura flutuante, a fim de excluir as produções que não fossem atinentes à formação de professores. Sendo assim, considerou-se como estudos relativos a essa temática os que versavam sobre formação inicial e continuada, tendo como sujeitos de pesquisa estudantes em formação e/ou professores. Além disso, as resenhas também foram excluídas.

A leitura flutuante como estratégia de seleção resultou em 12 artigos, três publicados na RBCE, um na RBEFE, quatro na Motrivivência, dois na REF-UEM, um na Movimento e um na Pensar a Prática. Após essa seleção todos os textos foram submetidos a uma nova rodada de leitura na íntegra, a fim de confirmar, em última análise, se todos estavam relacionados à Teoria das Representações Sociais, Formação de Professores e Educação Física. Essas estratégias metodológicas resultaram em um montante de 12 artigos que compuseram o corpus de análise do estudo.

Para a de discussão temática do estado do conhecimento, emergiram as seguintes variáveis para efeito de análise: referencial teórico; tipos de abordagem da teoria; objetivo dos artigos; sujeitos da pesquisa; técnica de coleta de dados.

\section{RESULTADOS E DISCUSSÃO}

A busca por artigos sobre Representações Sociais, Formação de Professores e Educação Física nos principais periódicos da área resultou em 12 manuscritos que foram relacionados no Quadro 1 de acordo com o ano da publicação, o título do texto, a autoria e o título do periódico.

Quadro 1 - Relação dos artigos selecionados nas revistas pesquisadas em ordem cronológica

\begin{tabular}{|l|l|l|l|}
\hline Ano & Artigo & Autoria & Periódico \\
\hline
\end{tabular}




\begin{tabular}{|c|c|c|c|}
\hline 2002 & $\begin{array}{l}\text { Educação física e homossexualidade: } \\
\text { investigando as representações sociais dos } \\
\text { estudantes do centro de desportos/UFSC }\end{array}$ & Rosa & Motrivivência \\
\hline 2006 & $\begin{array}{l}\text { A auto-representação da saúde dos } \\
\text { professores de educação física de academias }\end{array}$ & $\begin{array}{l}\text { Espírito-Santo e } \\
\text { Mourão }\end{array}$ & $\begin{array}{l}\text { Revista Brasileira de } \\
\text { Ciências do Esporte }\end{array}$ \\
\hline 2009 & $\begin{array}{c}\text { As representações sociais do ato pedagógico } \\
\text { dos professores de educação física que } \\
\text { atuam no ensino fundamental no município } \\
\text { do Rio de Janeiro }\end{array}$ & Retondar & Motrivivência \\
\hline 2012 & $\begin{array}{l}\text { Representações sociais sobre a educação } \\
\text { física na educação infantil }\end{array}$ & $\begin{array}{l}\text { Mello, Rodrigues, } \\
\text { Santos, Costa e } \\
\text { Votre }\end{array}$ & $\begin{array}{l}\text { Revista de Educação } \\
\text { Física - UEM }\end{array}$ \\
\hline 2013 & $\begin{array}{l}\text { A representação social de estudantes de } \\
\text { educação física sobre o campo profissional }\end{array}$ & $\begin{array}{l}\text { Osório, Assis e } \\
\text { Pereira }\end{array}$ & Pensar a Prática \\
\hline 2014 & $\begin{array}{c}\text { Ancoragem da representação social da } \\
\text { educação física escolar nas abordagens } \\
\text { teóricas da educação física }\end{array}$ & $\begin{array}{l}\text { Vasconcelos e } \\
\text { Campos }\end{array}$ & Motrivivênica \\
\hline 2015 & $\begin{array}{c}\text { A representação social de formação } \\
\text { continuada de professores de educação física } \\
\text { da rede estadual do Espírito Santo }\end{array}$ & $\begin{array}{l}\text { Walk, Caparroz e } \\
\text { Bracht }\end{array}$ & $\begin{array}{l}\text { Revista Brasileira de } \\
\text { Educação Física e } \\
\text { Esporte }\end{array}$ \\
\hline 2017 & $\begin{array}{c}\text { As representações sociais de estudantes de } \\
\text { educação física sobre a formação de } \\
\text { professores }\end{array}$ & $\begin{array}{l}\text { Triani, Magalhães } \\
\text { Júnior e Novikoff }\end{array}$ & Movimento \\
\hline 2017 & $\begin{array}{l}\text { As representações sociais dos discentes do } \\
\text { curso de licenciatura em educação física na } \\
\text { Unemat-Cáceres/MT sobre o trabalho com o } \\
\text { corpo/aluno na escola: olhares para os } \\
\text { conteúdos da educação física } \\
\end{array}$ & Stroher e Musis & $\begin{array}{l}\text { Revista Brasileira de } \\
\text { Ciências do Esporte }\end{array}$ \\
\hline 2018 & $\begin{array}{l}\text { As representações de corpo feminino nos } \\
\text { discursos de mestrandas em educação física }\end{array}$ & Silva, Pires e Lara & $\begin{array}{l}\text { Revista Brasileira de } \\
\text { Ciências do Esporte }\end{array}$ \\
\hline 2019 & $\begin{array}{l}\text { As representações sociais de bacharelandos } \\
\text { sobre ser profissional de educação física }\end{array}$ & $\begin{array}{c}\text { Triani, Barros, } \\
\text { Magalhães Júnior e } \\
\text { Telles }\end{array}$ & $\begin{array}{l}\text { Revista de Educação } \\
\text { Física - UEM }\end{array}$ \\
\hline 2020 & $\begin{array}{l}\text { Representações docentes de educação física } \\
\text { escolar: singularidades produzidas pelos } \\
\text { projetos de trabalho }\end{array}$ & Coelho e Bossle & Motrivivência \\
\hline
\end{tabular}

Fonte: $\mathrm{o}$ autor.

A Quadro 1 apresenta a relação de todos os artigos encontrados que foram publicados em periódicos acadêmico-científicos do campo da Educação Física brasileira. Nota-se que do ano de publicação do primeiro artigo até 2020 são quase 20 anos de apropriação da Teoria das Representações Sociais para discussão de temáticas atinentes à formação de professores na educação física, embora com média $(0,6)$ de publicação de menos de um artigo por ano.

Um estudo anterior (SOUSA et al., 2018), embora não tenha tido como foco a formação de professores, identificou uma média de 0,85 artigos sobre representações sociais por ano em uma 
pesquisa realizada até 2016. Além disso, observou regularidade de um artigo por ano a partir de 2009. Já no contexto do estudo em tela, parece que a regularidade se manifesta a partir do ano de 2012.

Dos 12 artigos que compuseram o corpus de análise, menos da metade, cinco artigos, tematizaram a formação de professores no contexto da graduação, isto é, na formação inicial. Já os demais estudos tiveram como objeto das representações sociais a formação continuada. Assim sendo, é possível observar que a apropriação da Teoria das Representações Sociais no que tange à formação de professores no campo da Educação Física está mais inclinada para a temática da formação continuada.

É importante sinalizar que os periódicos "Revista Brasileira de Atividade Física e Saúde" e "Revista Brasileira de Cineantropometria e Movimento Humano" não publicaram nenhum artigo sobre a temática. Esse resultado pode ter sido observado porque esses periódicos, ainda que sejam da área de Educação Física (LAZZAROTTI FILHO, 2018), não têm como foco e escopo produções de cunho sociocultural e pedagógico (MANOEL; CARVALHO, 2011).

No que tange à variável referencial teórico, embora esteja assim denominada, não é propriamente dito o referencial teórico-metodológico que norteou o artigo em sua inteireza, mas às bases teóricas, os textos sobre representações sociais utilizados como fundamentação ou análise dos estudos. Os achados sobre essa variável são ilustrados na Quadro 2.

Quadro 2 - Referências utilizadas como base teórica de análise dos estudos encontrados

\begin{tabular}{|c|c|l|}
\hline \multirow{2}{*}{ Base teórica } & $\begin{array}{c}\text { Númer } \\
\text { o de } \\
\text { citaçõe } \\
\text { S }\end{array}$ & \multicolumn{1}{|c|}{ Referências } \\
\hline \multirow{5}{*}{ Serge Moscovici } & 4 & $\begin{array}{l}\text { MOSCOVICI, S. Representações sociais: investigações em } \\
\text { psicologia social. Petrópolis: Vozes, 2003. }\end{array}$ \\
\cline { 2 - 4 } & 4 & $\begin{array}{l}\text { MOSCOVICI, S. Representação social da psicanálise. Rio de } \\
\text { Janeiro: Zahar; 1978. }\end{array}$ \\
\cline { 2 - 4 } Denise Jodelet & 2 & $\begin{array}{l}\text { MOSCOVICI, S. A Psicanálise, sua imagem e seu público. } \\
\text { Petrópolis: Vozes, 2012. }\end{array}$ \\
\cline { 2 - 4 } & 4 & $\begin{array}{l}\text { JODELET, D. (Org.). As representações sociais. Rio de Janeiro: } \\
\text { Eduerj, 2001. }\end{array}$ \\
\cline { 2 - 4 } & 1 & $\begin{array}{l}\text { JODELET, D. Loucuras e representações. Petrópolis: Vozes, 2005. } \\
\text { teoria. Rio de Janeiro: Mimeografado, 1988. }\end{array}$ \\
\hline \multirow{2}{*}{ Jean Abric } & 3 & $\begin{array}{l}\text { ABRIC, J. C. A abordagem estrutural das representações sociais. } \\
\text { In.: MOREIRA, A. S. P.; OLIVEIRA, D. C. (Org.). Estudos } \\
\text { interdisciplinares de representações sociais. 2. ed. Goiânia: Ed. AB, } \\
\text { 2000. }\end{array}$ \\
\hline
\end{tabular}




\begin{tabular}{|c|c|c|}
\hline & 2 & $\begin{array}{l}\text { ABRIC, J. C. Práticas sociales y representaciones. México: } \\
\text { PressesUniversitaires de France, } 2001 \text {. }\end{array}$ \\
\hline & 1 & $\begin{array}{l}\text { Abric, J. C. O estudo experimental das representações sociais. In.: } \\
\text { JODELET, D. (Org.). As representações sociais. Rio de Janeiro: } \\
\text { EdUERJ, 2001. }\end{array}$ \\
\hline \multirow{4}{*}{ Celso Sá } & 2 & $\begin{array}{l}\text { SÁ, C. P. A construção do objeto de pesquisa em representações } \\
\text { sociais. Rio de Janeiro: EdUERJ, } 1998 \text {. }\end{array}$ \\
\hline & 2 & $\begin{array}{l}\text { SÁ, C. P. Núcleo Central das representações sociais. } 2 \text { ed. rev. } \\
\text { Petrópolis: Vozes, } 2002 .\end{array}$ \\
\hline & 1 & $\begin{array}{l}\text { SÁ, C. P. Representações sociais: teoria e pesquisa do núcleo } \\
\text { central. Temas em Psicologia, v. } 3 \text {, n. 1. p.19-33, } 1996 .\end{array}$ \\
\hline & 1 & $\begin{array}{l}\text { SÁ, C. P. O estudo das representações sociais no Brasil. Revista de } \\
\text { Ciências Humanas, Ed. Especial, p. 11-32, } 2000 .\end{array}$ \\
\hline $\begin{array}{l}\text { Maria Cecília } \\
\text { Minayo }\end{array}$ & 2 & $\begin{array}{l}\text { MINAYO, M. C. S. O conceito de representações sociais dentro da } \\
\text { sociologia clássica. In.: GUARESCHI, P.; JOVCHELOVITCH, S. } \\
\text { Textos em representações. } 2 \text { ed. Petrópolis: Vozes, } 1995 .\end{array}$ \\
\hline $\begin{array}{l}\text { Pedro Humberto } \\
\text { Campos }\end{array}$ & 2 & $\begin{array}{l}\text { CAMPOS, P. H. A abordagem estrutural e o estudo das relações } \\
\text { entre as práticas e representações sociais. In.: CAMPOS, P. H. F.; } \\
\text { LOUREIRO, M. C. da S. (Org.). Representações sociais e práticas } \\
\text { educativas. Goiânia: Ed. UCG, 2003. }\end{array}$ \\
\hline $\begin{array}{l}\text { MariseteHorochovs } \\
\text { ki }\end{array}$ & 2 & $\begin{array}{l}\text { HOROCHOVSKI, M. T. H. Representações sociais: Delineamentos } \\
\text { de uma categoria analítica. Em Tese, v. 1, n. 2, p. 92-106, } 2004 .\end{array}$ \\
\hline Sebastião Votre & 2 & $\begin{array}{l}\text { VOTRE, S. J. (Org.). Imaginário e representações sociais em } \\
\text { educação física, esporte e lazer. Rio de Janeiro: Editora Gama } \\
\text { Filho, } 2001 \text {. }\end{array}$ \\
\hline Mary Jane Spink & 1 & $\begin{array}{l}\text { SPINK, M. J. O conhecimento no cotidiano: as representações } \\
\text { sociais na perspectiva da psicologia social. São Paulo: Brasiliense, } \\
1995 \text {. }\end{array}$ \\
\hline $\begin{array}{c}\text { Alda } \\
\text { Alves-Mazzotti } \\
\end{array}$ & 1 & $\begin{array}{l}\text { ALVES-MAZZOTTI, A. J. Representações sociais: aspectos } \\
\text { teóricos e aplicações à educação. Múlt Leituras, } 2008 .\end{array}$ \\
\hline Pedrinho Guareschi & 1 & $\begin{array}{l}\text { GUARESCHI, P. Representações sociais, mídia e movimentos } \\
\text { sociais. In.: GUARESCHI, P.; HERNANDEZ, A.; CÁRDENAS, } \\
\text { M. (Orgs). Representações sociais em movimento. Psicologia do } \\
\text { ativismo político. Porto Alegre: EdiPUCRS, } 2010 \text {. }\end{array}$ \\
\hline
\end{tabular}

Fonte: $\mathrm{o}$ autor.

Nota-se que as obras mais adotadas como bases teóricas são as de Moscovici, seguido de Jodelet, Abric e Sá. Os dois primeiros também são os mais comumente citados nos estudos em representações sociais (TRIANI; NOVIKOFF, 2020) e em representações sociais na educação física (SOUSA et al., 2018). Os trabalhos publicados por Jodelet são conhecidos como aqueles que seguem mais fielmente as proposições iniciais de Moscovici, sendo assim, é comum que esses dois autores sejam citados em um mesmo estudo. Por outro lado, Abric e Sá correspondem a bases teóricas vinculadas a teoria que seguem outra via em estudos em representações sociais. Nesse contexto, de acordo com Triani e Novikoff (2020), Abric propôs uma abordagem das representações sociais alternativa à defendida inicialmente por Moscovici, a partir de um olhar estrutural sobre o 
fenômeno. Além disso, Sá, por sua vez, dos quatro mais citados é o único autor brasileiro, produziu contribuições importantes para o campo das representações sociais, sendo a Teoria do Núcleo Central (SÁ, 1996) a mais conhecida.

Os demais autores citados nas produções encontradas não constituíram um referencial teórico para os trabalhos produzidos, mas bases teóricas que apresentam leituras contemporâneas e avanços no que concerne à teoria, do ponto de visto do contexto brasileiro. Embora o número de citações não seja alto, esses autores possuem uma grande quantidade de produções sobre representações sociais, dentro dos seus respectivos campos de intervenção acadêmica. Cabe sinalizar que Votre, citado em dois dos 12 artigos, embora não tenha formação inicial em Educação Física, atuou mais de 20 anos no Programa de Pós-Graduação em Educação Física por meio do grupo de pesquisa denominado de "Imaginário Social da Educação Física, do Esporte e do Lazer" a partir da linha de pesquisa "representações sociais da educação física, do esporte e do lazer" da extinta Universidade Gama Filho, no Rio de Janeiro (RESENDE; VOTRE, 2003).

De acordo com Triani e Novikoff (2020), existem três formas de abordagem da Teoria das Representações Sociais: a abordagem processual, difundida por Jodelet; a abordagem estrutural, defendida por Abric, também conhecida como Escola do Midi; e a abordagem societal, proposta por Doise, também denominada de Escola de Genebra. Adicionalmente, ao revisitar a literatura sobre a temática é possível encontrar uma quarta, intitulada de abordagem radical das representações sociais, proposta por Votre, Alves e Melillo (2010). Diante das diferentes propostas existentes, uma das variáveis de análise foi o tipo de abordagem utilizada, conforme ilustra a Quadro3.

Quadro 3 - Abordagem da Teoria das Representações Sociais utilizada nos artigos selecionados

\begin{tabular}{|c|c|}
\hline Abordagem & Citação do Estudo \\
\hline \multirow{4}{*}{$\begin{array}{c}\text { Abordagem Processual das Representações } \\
\text { Sociais }\end{array}$} & Triani, Magalhães Júnior e Novikoff (2017) \\
\cline { 2 - 2 } & Espírito-Santo e Mourão (2006) \\
\cline { 2 - 2 } & Silva, Pires e Lara (2018) \\
\cline { 2 - 2 } & Coelho e Bossle (2020) \\
\cline { 2 - 2 } Abordagem Estrutural das Representações Sociais & Retondar (2009) \\
\cline { 2 - 2 } & Rosa (2002) \\
\cline { 2 - 2 } & Osório, Assis e Pereira (2013) \\
\cline { 2 - 2 } & Vasconcelos e Campos (2014) \\
\cline { 2 - 2 } & Walk, Caparroz e Bracht (2015) \\
\cline { 2 - 2 } & Stroher e Musis (2017) \\
\cline { 2 - 2 } & Triani, Barros, Magalhães Júnior e Telles \\
& (2019) \\
\hline Abordagem Societal das Representações Sociais & - \\
\hline Abordagem Radical das Representações Sociais & Mello, Rodrigues, Santos, Costa e Votre (2012) \\
\hline
\end{tabular}

Fonte: o autor. 
OQuadro3 apresenta a citação dos estudos contemplados para efeito de análise e a forma de abordagem da Teoria das Representações Sociais adotada. Nesse contexto, observa-se um equilíbrio entre as abordagens processual e estrutural, tendo a segundo um estudo a mais de diferença em relação à primeira. Esses achados corroboram com os resultados da investigação de Triani e Novikoff (2020) sobre o estado do conhecimento em representações sociais na formação de professores, na medida em que observaram que as abordagens processual e estrutural foram as mais adotadas em dissertações e teses sobre a temática.

Nota-se também que nenhum dos estudos que compuseram o corpus de análise adotou a abordagem societal das representações sociais. De acordo com Almeida (2009), essa é a menos conhecida no Brasil. Sobre essa ausência, o mapeamento produzido por Sousa et al (2018) identificou que nenhum dos artigos que compuseram o seu estudo citou a abordagem proposta por Doise, bem como a revisão sobre as dissertações e teses (TRIANI; NOVIKOFF, 2020), que também não identificou nenhum trabalho até 2015 que tenha abordado a referida abordagem.

Sobre a "abordagem radical das representações sociais" (VOTRE; ALVES; MELLILO, 2010), é importante assinalar que nenhum estudo fora do campo acadêmico/científico da educação física foi encontrado sobre essa forma de abordagem da Teoria das Representações Sociais. Desse modo, faz-se necessário esclarecer que essa abordagem é semelhante à denominada processual, principalmente pela característica qualitativa (SÁ, 2000; ALMEIDA, 2009), tendo como característica diferencial a utilização do método da etnografia adotado de maneira associada à entrevista, grupo focal e análise do discurso.

O Estado do Conhecimento (ROMANOWSKI; ENS, 2006), dentre o levantamentos das variáveis a serem discutidas, prevê também a análise contextual do objetivo do estudo. Nesse sentido, o Quadro 4 apresenta o objetivo proposto por cada uma das investigações que fizeram parte do corpus da pesquisa.

Quadro 4 - Citação e objetivo das produções ao adotar a Teoria das Representações Sociais

\begin{tabular}{|c|l|}
\hline Citação & \multicolumn{1}{|c|}{ Objetivo } \\
\hline Rosa (2002) & $\begin{array}{l}\text { Investigar quais as representações sociais de professores/as em } \\
\text { formação em relação à homossexualidade nas diversas práticas } \\
\text { pedagógicas do curso deEducação Física da Universidade Federal de } \\
\text { Santa Catarina }\end{array}$ \\
\hline $\begin{array}{l}\text { Espírito-Santo e } \\
\text { Mourão (2006) }\end{array}$ & $\begin{array}{l}\text { Conhecer a saúde representada pelos professores de educação física que } \\
\text { atuam em mega academias do Rio de Janeiro }\end{array}$ \\
\hline
\end{tabular}




\begin{tabular}{|c|c|}
\hline Retondar (2009) & $\begin{array}{l}\text { Identificar as representações sociais do ato pedagógico dos professores } \\
\text { de educação física que atuam no ensino fundamental no Município do } \\
\text { Rio de Janeiro }\end{array}$ \\
\hline $\begin{array}{l}\text { Mello, Rodrigues, } \\
\text { Santos, Costa e Votre } \\
(2012)\end{array}$ & $\begin{array}{l}\text { Identificar e discutir as representações sociais que professores de um } \\
\text { Centro Municipal de Educação Infantil de Vitória/ES possuem sobre a } \\
\text { Educação Física }\end{array}$ \\
\hline $\begin{array}{l}\text { Osório, Assis e Pereira } \\
\text { (2013) }\end{array}$ & $\begin{array}{l}\text { Analisar a representação dos alunos de graduação de Educação Física } \\
\text { sobre o campo e a função de professor, com expectativa de identificar } \\
\text { também seus anseios e projeções profissionais. }\end{array}$ \\
\hline $\begin{array}{l}\text { Vasconcelos e Campos } \\
\text { (2014) }\end{array}$ & $\begin{array}{l}\text { Investigar a prática da Educação Física nas escolas sob a ótica da Teoria } \\
\text { das Representações Sociais na busca da identificação da ancoragem das } \\
\text { representações sociais nos Modelos Teóricos desta disciplina }\end{array}$ \\
\hline $\begin{array}{c}\text { Walk, Caparroz e } \\
\text { Bracht (2015) }\end{array}$ & $\begin{array}{l}\text { Compreender a representação social dos professores de Educação Física } \\
\text { da Rede Estadual do Espírito Santo em relação a sua formação } \\
\text { continuada. }\end{array}$ \\
\hline $\begin{array}{l}\text { Triani, Magalhães } \\
\text { Júnior e Novikoff } \\
\qquad(2017)\end{array}$ & $\begin{array}{l}\text { Identificar e analisar algumas das representações sociais possíveis que os } \\
\text { estudantes do curso de Educação Física de uma universidade privada na } \\
\text { Baixada Fluminense do Rio de Janeiro podem apresentar sobre a } \\
\text { formação de professores. }\end{array}$ \\
\hline Stroher e Musis (2017) & $\begin{array}{l}\text { Encontrar e analisar as representações sociais que os discentes do curso } \\
\text { de licenciatura em educação física da Universidade do Estado de Mato } \\
\text { Grosso-Cáceres/MT têm acerca do trabalho com o corpo/aluno na escola. }\end{array}$ \\
\hline $\begin{array}{l}\text { Silva, Pires e Lara } \\
\text { (2018) }\end{array}$ & $\begin{array}{l}\text { Identificar e analisar as representações sociais sobre corpo instituídas no } \\
\text { imaginário de mestrandas vinculadas a programa de pós-graduação } \\
\text { stricto-sensu em educação física de universidades públicas do Estado do } \\
\text { Paraná. }\end{array}$ \\
\hline $\begin{array}{l}\text { Triani, Barros, } \\
\text { Magalhães Júnior e } \\
\text { Telles (2019) } \\
\end{array}$ & $\begin{array}{l}\text { Identificar e discutir as representações sociais que estudantes do curso de } \\
\text { bacharelado em educação física associam ao ser profissional de educação } \\
\text { física. }\end{array}$ \\
\hline Coelho e Bossle (2020) & $\begin{array}{l}\text { Compreender como um currículo organizado por projetos de trabalho } \\
\text { produz representações singulares sobre Educação Física escolar em um } \\
\text { coletivo docente }\end{array}$ \\
\hline
\end{tabular}

Fonte: o autor.

Há em comum, no objetivo de cada artigo, a busca pela identificação, análise ou conhecimento das representações sociais de um determinado fenômeno. Sousa et al (2018) observou que, dentre os trabalhos revisados em seu estudo, grande parte buscou conhecer e compreender as representações sociais, achado que coaduna com os resultados encontrados no mapeamento desenvolvido no estudo em tela.

De acordo com Triani e Telles (2019), um dos objetivos da pesquisa em representações sociais é identificar quais são as representações sociais compartilhadas por grupos sociais, a fim de discuti-las no campo científico. Adicionalmente, Jodelet (2001) afirma que as representações sociais são conhecimentos socialmente compartilhados, sendo assim, parece que "conhecer", 
“identificar" e "analisar" quais são esses conhecimentos pode contribuir para compreender o comportamento do grupo social estudado.

De acordo com Gonçalves e Sousa (2015) as representações sociais levam em conta os pontos de vista dos sujeitos e dos grupos, esses que são necessários para compreensão do dinamismo social das mudanças das partes que a compõe. Nesse sentido, os objetivos dos artigos mapeados parecem estar buscando conhecer quais são essas representações sociais compartilhadas na formação inicial e na continuada de professores, a fim de discutir a natureza dos processos formativos.

Gonçalves e Sousa (2015) afirmam que o conhecimento sobre a subjetividade docente, partindo da análise das representações sociais que a constitui, pode ser um caminho possível para compreender as práticas cotidianas do professor. Nesse sentido, a pesquisa sobre formação de professores do ponto de vista das representações sociais parece indicar quais são os valores, ideias e práticas que possibilitam compreender como os professores se orientam, como se constituem enquanto grupo social e as características que compõem sua subjetividade, além de analisar como que enquanto sujeitos exercem a docência.

Os sujeitos que participam dos estudos em representações sociais na/para a formação de professores constituem uma valorosa variável. Desse modo, o Quadro 5 apresenta o resultado da classificação dos artigos mapeados de acordo com os participantes.

Quadro 5 - Sujeitos que participaram da pesquisa por artigo

\begin{tabular}{|c|l|}
\hline Sujeitos & \multicolumn{1}{|c|}{ Citação do Estudo } \\
\hline \multirow{2}{*}{ Estudantes de Graduação } & $\begin{array}{l}\text { Rosa (2002); Osório, Assis e Pereira (2013); Triani, Magalhães } \\
\text { Júnior e Novikoff (2017); Stroher e Musis (2017); Triani, Barros, } \\
\text { Magalhães Júnior e Telles (2019) }\end{array}$ \\
\hline Estudantes de Pós-Graduação & Silva, Pires e Lara (2018) \\
\hline Professores & $\begin{array}{l}\text { Espírito-Santo e Mourão (2006); Retondar (2009); Mello, } \\
\text { Rodrigues, Santos, Costa e Votre (2012); Vasconcelos e Campos } \\
\text { (2014); Walk, Caparroz e Bracht (2015); Coelho e Bossle (2020) }\end{array}$ \\
\hline
\end{tabular}

Fonte: o autor.

Ao direcionar o olhar para os sujeitos de maior prevalência nos estudos em representações sociais sobre formação de professores na educação física, nota-se que dos 12 artigos que compuseram o corpus de análise, seis tiveram como sujeitos professores atuantes na prática pedagógica, cinco estudantes de graduação e um deles estudantes de pós-graduação. Desse modo, observa-se que professores e acadêmicos, para a investigação em tela, constituem os sujeitos mais comuns nos estudos em representações sociais sobre formação de professores na educação física. 
Nessa mesma perspectiva, Triani e Novikoff (2020) desenvolveram o estado do conhecimento sobre os estudos em representações sociais na formação de professores e observaram que dos trabalhos que compuseram sua amostra, os sujeitos mais recorrentes foram os professores em 85 das produções, seguido dos acadêmicos com 42. Sendo assim, professores e alunos são os sujeitos que mais participam das pesquisas em formação de professores do ponto de vista das representações sociais, achados que coadunam com o que se pode observar no Quadro 5 do estudo em tela.

Ao partir da proposição de Alves-Mazzotti (2008), a de que um objeto social é sempre apreendido com algo associado a um grupo e a suas intenções e objetivos, é possível assinalar que embora existam forças externas e forças internas que correspondem a variáveis que influenciam o contexto da formação de professores, os estudantes e os professores parecem ser os sujeitos que mais são associados às produções que têm essa temática como objeto de estudo.

É importante ressaltar que os estudos analisados em representações sociais na formação de professores em educação física, em todos os casos, constituíram grupos sociais para a produção da investigação. As pesquisas buscaram conhecer as representações sociais de determinado grupo social, os quais foram grupo de professores, grupo de acadêmicos ou de pós-graduandos. Sobre a constituição de grupos sociais, Moscovici (2012) afirma que a existência dos grupos existe e pode ser identificada a partir de certo grau de associação entre seus membros. Nesse sentido, considerando o contexto do estudo aqui desenvolvido parece válido que professores e estudantes constituam grupos, na medida em que partilham de semelhantes condições, isto é, passam pelos mesmos problemas, ministram aulas, seguem planejamentos, participam de reuniões pedagógicas e outras. Adicionalmente Jodelet (1989) assinala que o grupo partilha de um tipo de relação com o mundo, de valores, modos de vida, constrangimentos e desejos que estão associados à filiação grupal necessária à manutenção da identidade social.

Em se tratando da relação do sujeito com a formação de professores, é oportuno perceber que quando o objeto das representações sociais trata-se da formação inicial os estudantes de graduação constituem os sujeitos mais comuns nos estudos (ROSA, 2002; OSÓRIO; ASSIS; PEREIRA, 2013; TRIANI; MAGALHÃES JÚNIOR; NOVIKOFF, 2017; STROHER; MUSIS, 2017; TRIANI et al., 2019). Por outro lado, quando se pretende investigar a formação de professores na perspectiva da formação continuada os docentes atuantes na prática pedagógica parecem ser os sujeitos escolhidos (ESPÍRITO-SANTO; MOURÃO, 2006; RETONDAR, 2009; MELLO et al., 2012; VASCONCELOS; CAMPOS, 2014; WALK; CAPARROZ; BRACHT, 2015; COELHO; BOSSLE, 2020), além dos estudantes de pós-graduação (SILVA; PIRES; LARA, 2018). 
Além da análise dos sujeitos da pesquisa, outra variável que foi objeto de análise se refere à forma como os pesquisadores fizeram contato ou obtiveram, conheceram ou buscaram identificar as representações sociais, isto é, às técnicas utilizadas para coletar dados, conforme ilustra o Quadro 6.

Quadro 6 - As técnicas de coleta de dados adotadas nos estudos sobre representações sociais na formação de professores em educação física

\begin{tabular}{|c|l|}
\hline $\begin{array}{c}\text { Técnica de Coleta de } \\
\text { Dados }\end{array}$ & \multicolumn{1}{|c|}{ Citação do Estudo } \\
\hline Diário de Campo & $\begin{array}{l}\text { Mello, Rodrigues, Santos, Costa e Votre (2012); Coelho e Bossle } \\
(2020)\end{array}$ \\
\hline Entrevista & $\begin{array}{l}\text { Rosa (2002); Espírito-Santo e Mourão (2006); Mello, Rodrigues, } \\
\text { Santos, Costa e Votre (2012); Silva, Pires e Lara (2018); Coelho e } \\
\text { Bossle (2020) }\end{array}$ \\
\hline $\begin{array}{c}\text { Teste de Associação Livre } \\
\text { de Palavras }\end{array}$ & $\begin{array}{l}\text { Osório, Assis e Pereira (2013); Walk, Caparroz e Bracht (2015); } \\
\text { Stroher e Musis (2017); Triani, Barros, Magalhães Júnior e Telles } \\
\text { (2019) }\end{array}$ \\
\hline Questionário & $\begin{array}{l}\text { Retondar (2009); Vasconcelos e Campos (2014); Triani, Magalhães } \\
\text { Júnior e Novikoff (2017) }\end{array}$ \\
\hline
\end{tabular}

Fonte: o autor.

Os resultados apresentados no Quadro 6 demonstram que as técnicas mais frequentemente utilizadas em estudos sobre representações sociais acerca da formação de professores na educação física são Entrevista, Teste de Associação Livre de Palavras, Questionário e Diário de Campo, respectivamente.

A técnica de coleta de dados possui associação com o tipo de abordagem das representações sociais adotada na pesquisa, comumente a Entrevista e o Diário de Campo são instrumentos utilizados em estudos cuja abordagem adotada é a processual (JODELET, 2001; TRIANI; NOVIKOFF, 2020). Cabe ressaltar que o próprio Moscovici (2012) ao desenvolver sua tese que deu origem à Teoria das Representações Sociais adotou a Entrevista como procedimento de coleta de dados no estudo sobre representações sociais da psicanálise.

O instrumento metodológico ou técnica de coleta de dados denominada de Teste de Associação Livre de Palavras (SÁ; ARRUDA, 2000) corresponde a um método que busca identificar a estrutura de como estão organizados os elementos que constituem as representações sociais (CAMPOS, 2003; ALVES-MAZZOTTI, 2008; GONÇALVES; SOUSA, 2015), instrumento adotado hegemonicamente em pesquisas de abordagem estrutural das representações sociais.

O questionário é uma técnica de coleta de dados amplamente utilizada no campo da educação física (LÜDORF, 2017), bem como nos estudos em representações sociais sobre formação de professores (TRIANI; NOVIKOFF, 2020). Contudo, diferentemente do Teste de Associação 
Livre de Palavras, os questionários são variáveis, ou seja, são construídos especificamente para atender os objetivos da pesquisa, achados que podem ser observado no estudo de Retondar (2009) que elaborou um questionário para pesquisa com professores no município, no de Vasconcelos e Campos (2014) que compôs um específico para docentes do Ensino Fundamental, e ainda Triani, Magalhães Júnior e Novikoff (2017) que adotaram a mesma técnica direcionando as perguntas para estudantes de graduação. Cabe ressaltar que mesmo existindo a possibilidade de se desenvolver pesquisa a partir da abordagem estrutural das representações sociais, o questionário tem sido uma técnica utilizada principalmente nas produções de abordagem processual com características de pesquisa qualitativa.

\section{CONSIDERAÇÕES FINAIS}

A identificação de como a Teoria das Representações Sociais vem sendo disseminada nas principais produções periódicas da educação física enquanto área de conhecimento, bem como as discussões sobre a formação de professores no campo, do ponto de vista da teoria, foi possível a partir do mapeamento da produção científica presente nos periódicos brasileiros.

Os desfechos observados na pesquisa demonstram que a Teoria das Representações Sociais, no que tange à formação de professores e educação física, está disseminada nos periódicos científicos que têm seu foco e escopo direcionado para as pesquisas com ênfase nas Ciências Humanas e Sociais e/ou nas subáreas sociocultural e pedagógica da Educação Física, embora o quantitativo de trabalhos não seja expressivo.

Ao desenvolver uma investigação a partir do estado do conhecimento frente a Teorias das Representações Sociais sobre a formação de professores na educação física, notou-se que a área tem se apropriado de diferentes abordagens que compõem o arcabouço teórico das representações sociais, bem como de múltiplas estratégias no que se refere aos métodos e técnicas de pesquisa.

Portanto, a disseminação da Teoria das Representações Sociais nos estudos sobre formação de professores na educação física, ainda que aparentemente esteja consolidada nos periódicos brasileiros do campo, necessita de futuras pesquisas que busquem explorar à temática em dissertações e teses, bem como na produção periódica brasileira de outras áreas do conhecimento, considerando a característica interdisciplinar da teoria. 


\section{REFERÊNCIAS}

ALMEIDA, Angela Maria de Oliveira. Abordagem societal das Representações Sociais. Sociedade e Estado, v. 24, n. 3, p. 713-737, 2009. Disponível em:

https://www.scielo.br/scielo.php?pid=S0102-69922009000300005\&script=sci_abstract\&tlng=pt. Acesso em: mai. 2020.

ALVES-MAZZOTTI, Alda Judith. Representações sociais: aspectos teóricos e aplicações à educação.

Revista Múltiplas Leituras, v. 1, n. 1, p. 18-43, 2008. Disponível em:

https://www.metodista.br/revistas/revistas-metodista/index.php/ML/article/download/1169/1181. Acesso em: mar. 2020.

CAMPOS, Pedro Humberto Faria. In: CAMPOS, Pedro Humberto Faria; LOUREIRO, Marcos Corrêa (Org.). Representações sociais e práticas educativas. Goiânia: Ed. UCG, 2003, p. 21-36.

GONÇALVES, Helenice Maia; SOUSA, Clarilza Prado. Articulações entre representações sociais e subjetividade: um estudo sobre a produção nacional entre 2000 e 2010. Revista Educação e Cultura Contemporânea, v. 12, n. 27, p. 258-288, 2015. Disponível em:

http://periodicos.estacio.br/index.php/reeduc/article/viewArticle/1260. Acesso em: jun. 2020.

JODELET, Denise. (Org.). As representações sociais. Rio de Janeiro: Eduerj, 2001.

JODELET, Denise. Représentationssociales: undomaine en expansion. In: JODELET, Denise. (Org.).

Lesreprésentationssociales. 1ed. Paris: PressesUniversitaires de France, 1989, p. 31-61.

LAZZAROTTI FILHO, Ari. O periodismo científico da educação física brasileira. Motrivivência, v. 30, n. 54, p. 35-50, 2018. Disponível em:

https://periodicos.ufsc.br/index.php/motrivivencia/article/view/2175-8042.2018v30n54p35. Acesso em: mai. 2020.

LUDORF, Silvia Maria Agatti. Metodologia da pesquisa: do projeto ao trabalho de conclusão de curso. Rio de Janeiro: Appris, 2017.

MANOEL, Edson Jesus; CARVALHO, Yara Maria. Pós-graduação na educação física brasileira: a atração (fatal) para a biodinâmica. Educação e Pesquisa, v. 37, n. 2, p. 389-406, 2011. Disponível em:

https://www.scielo.br/scielo.php?pid=S1517-97022011000200012\&script=sci_abstract\&tlng=pt. Acesso em: jun. 2020.

MOSCOVICI, Serge. A Psicanálise, sua imagem e seu público. Petrópolis: Vozes, 2012.

MOSCOVICI, Serge. Representações sociais: investigações em psicologia social. Petrópolis: Vozes, 2009.

RESENDE, Helder Guerra; VOTRE, Sebastião Josué. O programa de pós-graduação stricto sensu em educação física da Universidade Gama Filho: características, realizações e desafios. Revista Brasileira de Ciências do Esporte, v. 24, n. 2, p. 49-73, 2003. Disponível em:

http://www.rbce.cbce.org.br/index.php/RBCE/article/download/358/312. Acesso em: mai. 2020.

ROMANOWSKI, Joana Paulin; ENS, Romilda Teodora. As pesquisas denominadas do tipo "estado da arte" em educação. Revista Diálogo Educacional, v. 6,n. 19, p. 37-50, 2006. Disponível em:

https://periodicos.pucpr.br/index.php/dialogoeducacional/article/view/24176. Acesso em: mar. 2020.

SÁ, Celso Pereira; ARRUDA, Angela. O estudo das representações sociais no Brasil. Revista de Ciências Humanas, v. 3, edição especial, p. 11-31, 2000. Disponível em:

https://periodicos.ufsc.br/index.php/revistacfh/article/view/24121. Acesso em: mai. 2020. 
SÁ, Celso Pereira. Representações sociais: teoria e pesquisa do núcleo central. Temas em Psicologia, v. 3, n. 1, p. 19-33, 1996. Disponível em: http://pepsic.bvsalud.org/pdf/tp/v4n3/v4n3a02.pdf. Acesso em: jun. 2020.

RETONDAR, Jeferson José Moebus. As representações sociais do ato pedagógico dos professores de educação física que atuam no ensino fundamental no município do Rio de Janeiro. Motrivivência, v. 21, n. 32, p. 211-229, 2009. Disponível em:

https://periodicos.ufsc.br/index.php/motrivivencia/article/view/2175-8042.2009n32-33p211. Acesso em: mai. 2020.

SOUSA, Diego Petyk de et al. Apropriação da teoria das representações sociais pelo campo acadêmico/científico da educação física no Brasil: o estado do conhecimento (2004-2016). Pensar a Prática, v. 21, n. 4, p. 796-809, 2018. Disponível em: https://www.revistas.ufg.br/fef/article/view/49647. Acesso em: mar. 2020.

TRIANI, Felipe da Silva; MAGALHÃES JÚNIOR, Carlos Alberto de Oliveira; NOVIKOFF, Cristina. As representações sociais de estudantes de educação física sobre a formação de professores. Movimento, v. 23, n. 2, p. 575-586, 2017. Disponível em: https://seer.ufrgs.br/Movimento/article/view/68898/0. Acesso em: fev. 2020 .

TRIANI, Felipe da Silva; NOVIKOFF, Cristina. Representações sociais do corpo: o universo simbólico da formação de professores de educação física. Rio de Janeiro: Autografia, 2020.

TRIANI, Felipe da Silva; TELLES, Silvio de Cassio Costa. Representações sociais sobre os esportes de aventura na educação física. Interfaces da Educação, v. 10, n. 30, p. 246-267, 2019. Disponível em: https://periodicosonline.uems.br/index.php/interfaces/article/view/3946. Acesso em: mai. 2020.

VASCONCELOS, Fátima; CAMPOS, Pedro Humberto Faria. Ancoragem da representação social da Educação Física escolar nas abordagens teóricas da educação física. Motrivivência, v. 26, n. 43, p. 164-182, 2014. Disponível em:

https://periodicos.ufsc.br/index.php/motrivivencia/article/view/2175-8042.2014v26n43p164. Acesso em: mar. 2020.

VOTRE, Sebastião Josué; Alves, Ana Paula; MELILLO, Carlos Eduardo. Abordagem radical das representações sociais. Corpus etScientia, v. 6, n. 2, p. 11-18, 2010. Disponível em:

https://core.ac.uk/download/pdf/229103057.pdf. Acesso em: fev. 2020.

\section{NOTAS DE AUTOR}

AGRADECIMENTOS - Não se aplica.

\section{FINANCIAMENTO}

A pesquisa contou com o apoio na forma de bolsa do Programa Pesquisa Produtividade da UNESA.

CONSENTIMENTO DE USO DE IMAGEM - Não se aplica.

APROVAÇÃO DE COMITÊ DE ÉTICA EM PESQUISA - Não se aplica.

CONFLITO DE INTERESSES - Não se aplica.

\section{LICENÇA DE USO}

Os autores cedem à Motrivivência- ISSN 2175-8042 os direitos exclusivos de primeira publicação, com o trabalho simultaneamente licenciado sob a Licença CreativeCommonsAttribution Non-Comercial ShareAlike (CC BY-NC SA) 4.0 International. Esta licença permite que 
terceirosremixem, adaptem e criem a partir do trabalho publicado, desde que para fins não comerciais, atribuindo o devido crédito de autoria e publicação inicial neste periódico desde que adotem a mesma licença, compartilhar igual. Os autores têm autorização para assumir contratos adicionais separadamente, para distribuição não exclusiva da versão do trabalho publicada neste periódico (ex.: publicar em repositório institucional, em site pessoal, publicar uma tradução, ou como capítulo de livro), com reconhecimento de autoria e publicação inicial neste periódico, desde que para fins não comerciais e compartilhar com a mesma licença.

\section{PUBLISHER}

Universidade Federal de Santa Catarina. Programa de Pós-Graduação em Educação Física. LaboMídia - Laboratório e Observatório da Mídia Esportiva. Publicado no Portal de Periódicos UFSC. As ideias expressadas neste artigo são de responsabilidade de seus autores, não representando, necessariamente, a opinião dos editores ou da universidade.

\section{EDITORES}

Mauricio Roberto da Silva, Giovani de Lorenzi Pires, Rogério Santos Pereira.

\section{EDITOR DE SEÇÃO}

Rafael Matiuda Spinelli.

\section{REVISÃO DO MANUSCRITO E METADADOS}

João Caetano Prates Rocha; Keli Barreto.

\section{HISTÓRICO}

Recebido em: 18 de fevereiro de 2021.

Aprovado em: 27 de julho de 2020. 